\title{
Erratum to: Psychosocial distress in acute cancer patients assessed with an expert rating scale
}

Bianca Senf • Holger Brandt • Axel Dignass •

Rolf Kleinschmidt • Jochen Kaiser

Published online: 29 May 2010

(C) Springer-Verlag 2010

\section{Erratum to: Support Care Cancer}

\section{DOI 10.1007/s00520-010-0850-9}

The color legend to Figure 2 is incorrect. Dark gray bars show nondistressed patients, light gray bars show distressed patients.

The online version of the original article can be found at http://dx.doi. org/10.1007/s00520-010-0850-9.

B. Senf $(\varangle) \cdot$ A. Dignass $\cdot$ R. Kleinschmidt Medical Clinic, Markus Hospital,

Wilhelm-Epstein-Str. 2,

60431 Frankfurt am Main, Germany

e-mail: bianca.senf@fdk.info

B. Senf $\cdot$ J. Kaiser

Institute of Medical Psychology, Goethe University,

60528 Frankfurt am Main, Germany

H. Brandt

Institute of Psychology, Goethe University,

60054 Frankfurt am Main, Germany 